DAS PROJEKT DER DEUTSCHEN LITERATURGESCHICHTE 
Jürgen Fohrmann

\title{
DAS PROJEKT DER DEUTSCHEN LITERATURGESCHICHTE
}

\author{
Entstehung und Scheitern \\ einer nationalen Poesiegeschichtsschreibung \\ zwischen Humanismus und \\ Deutschem Kaiserreich
}

J.B. Metzlersche Verlagsbuchhandlung Stuttgart 
CIP-Titelaufnahme der Deutschen Bibliothek

Fohrmann, Jürgen:

Das Projekt der deutschen Literaturgeschichte : Entstehung und

Scheitern einer nationalen Poesiegeschichtsschreibung zwischen

Humanismus und Deutschem Kaiserreich / Jargen Fohrmann. -

Stuttgart : Metzler, 1989

Zugl.: Bielefeld, Univ., Habil.-Schr., 1988

ISBN 978-3-476-00660-8

ISBN 978-3-476-03278-2 (eBook)

DOI 10.1007/978-3-476-03278-2

Dieses Werk einschließlich aller seiner Teile ist urheberrechtlich geschatzt. Jede Verwertung außerhalb der engen Grenzen des Urheberrechtsgesetzes ist ohne Zustimmung des Verlages unzulässig und strafbar. Das gilt insbesondere fur Vervielfăltigungen, Übersetzungen, Mikroverfilmungen und die Einspeicherung in elektronischen Systemen.

(C) 1989 Springer-Verlag GmbH Deutschland

Ursprünglich erschienen bei J. B. Metzlersche Verlagsbuchhandlung und Carl Ernst Poeschel Verlag GmbH in Stuttgart 1989 


\title{
INHALTSVERZEICHNIS
}

\author{
EinLeItUNG \\ Seite 1
}

I

Das Projekt einer neuen Geschichte

Seite 3

1. Tradition, Wissen und Geschichte 3

2. Geschichtsschreibung als Herstellung von Zusammenhang 19

3. Geschichtsforschung, Geschichtsdarstellung und die "innere Geschichte" der Literatur 35

4. Konstruktion und Rekonstruktion 56

5. Rekonstruktionsprogramme 62

II

Nation als SUbJekt der Entelechie

Seite 69

1. Nationale Kulturtradition 69

2. Querelle der Nationen und Literaturgeschichte 74

3. Poesie und Beredsamkeit - auch der Deutschen. Nation als Ordnungskategorie klassifikatorischen Wissens 84

4. Der Plan einer deutschen Literaturgeschichte 87

5. Nation als Zentrum bei Herder 95

6. Das Deutsche als Ursprung. Das Konzept der Literaturgeschichte bei August Wilhelm und Friedrich Schlegel 99

7. Deutsche Universalităt 115

8. "Litteratur - Poesie - Nationallitteratur" 125

III

KUnST, LEBEN UND NATION

Seite 131

1. Die Neue Zeit und die Kritik 131

2. Varianten nationaler Entelechie 138 
Inhaltsverzeichnis

IV

Die Literaturgeschichte UND DER ÄSThetische Historismus

Seite 171

1. Die neue Definition der Poesie 171

2. Resümee aber Bildung 177

3. Geselligkeitskultur und Literaturgeschichte 184

$\mathrm{V}$

Wissenschaft, Philologie, Literaturgeschichte

Seite 211

1. Philologische Literaturgeschichte 211

2. Verdopplung der Sinndimension und Diffusionsprozesse 226

VI

Literaturgeschichte UND ERZiehUNG

Seite 241

SChLUSSBETRACHTUNG

Seite 260

Abbildungen zu Kapitel IV

Seite 264

Anmerkungen

Einleitung 272

Kapitel I 273

Kapitel II 288

Kapitel III 306

Kapitel IV 315

Kapitel V 321

Kapitel VI 332

LITERATURVERZEICHNIS

Seite 339

Personenregister

Seite 386 
Für Ilona 


\section{VORWORT}

Eine Studie, die theoretische Interessen mit umfassender Geschichtsrekonstruktion zu verbinden sucht, ist vielfachen Dank schuldig. Herzlich gedankt sei daher zunăchst Wilhelm Voßkamp, Karl Heinz Bohrer, Reinhart Koselleck und Harro Maller, die die Arbeit betreut haben. Herzlich gedankt sei weiterhin den Mitarbeitern des DFG-Projekts "Wissenschaftsgeschichte der deutschen Literaturwissenschaft" und hier insbesondere Holger Dainat, ohne den das V. Kapitel nicht in dieser Form hătte geschrieben werden kőnnen.

Vieles hat auch die stete Hilfeleistung wichtiger Bibliotheken ermöglicht: ohne die Büchersammlungen der Staatsbibliothek Preußischer Kulturbesitz Berlin, der Niedersåchsischen Landes- und Universitătsbibliothek Gottingen, des Ratsgymnasiums Bielefeld und ohne die mühevolle Beschaffungsarbeit der Universitătsbibliothek Bielefeld wäre die Arbeit nicht in so kurzer Zeit fertiggestellt worden.

Herzlich gedankt sei auch Frau Jegerlehner, die die Reinschrift des Manuskripts auf bewundernswerte Weise besorgt, der J.B. Metzlerschen Verlagsbuchhandlung, die die Arbeit in ihr Programm aufgenommen und Michael Vogt, der Korrektur gelesen hat.

Die Deutsche Forschungsgemeinschaft hat die Abfassung des Werkes (Habilitandenstipendium) und seine Drucklegung jeweils großzügig unterstützt.

Mein besonderer Dank gilt aber derjenigen, der die Arbeit zugeeignet ist.

Das "Projekt der deutschen Literaturgeschichte " ist von der "Fakultat for Linguistik und Literaturwissenschaft" der Universität Bielefeld im Januar 1988 als Habilitationsschrift angenommen worden.

Bielefeld, im November 1988

Järgen Fohrmann 
Die Literaturgeschichte ist die große Morgue wo jeder seine Toten aufsucht, die er liebt oder womit er verwandt ist. Wenn ich da unter so vielen unbedeutenden Leichen den Lessing oder den Herder sehe mit ihren erhabenen Menschengesichtern, dann pocht mir das Herz. Wie dürfte ich vorübergehen, ohne Euch flüchtig die blassen Lippen zu küssen!

(Heinrich Heine) 